\title{
DEVELOPMENT OF A RFID BASED LIBRARY MANAGEMENT SYSTEM AND USER ACCESS CONTROL
}

\author{
E. O. Edwards ${ }^{1}$ and P. E. Orukpe 2 ,* \\ 1 DEPARTMENT OF COMPUTER ENGINEERING, UNIVERSITY OF BENIN, NIGERIA. \\ 2 DEPARTMENT OF ELECTRICAL/ELECTRONIC ENGINEERING, UNIVERSITY OF BENIN, NIGERIA \\ E-mail addresses: 1 eddienuel@yahoo.com,2patience.orukpe@uniben.edu
}

\begin{abstract}
In this paper a radio frequency identification and detection (RFID) based library management system was developed that will enhance the use and management of library, the services being rendered can be managed with the help of software and hardware tools. This system use RFID technology to track books information in the library and the number of people that access the library. The device consists majorly of a RFID reader, a Bluetooth module, a microcontroller and the materials to be tracked are tagged with a RFID (a transponder). The unique IDs are stored in a PC running an application with other information on the materials into a database. Through these processes, books, library users with their information as well as their tag ID can easily be used for cataloging and user authentication. The device is designed to be mobile so that mixed books on shelves can easily be sorted out as the RFID reader moves across them. A model of the system was built, tested with several data and the result showed satisfactory improvement in the efficiency of the library management system.
\end{abstract}

Keywords: radio frequency identification (RFID), RFID tag, tag reader, visual basic and microcontroller.

\section{INTRODUCTION}

Over the years, efforts had been made to see library services such as book borrowing, user's information tracking etc. being provided in an effortless manner. Library Management Systems (LMS) are computer based systems that automate one or all functional areas of a typical library and have had a history of evolution going back to the mid-1950s. LMS have also been referred to as Integrated Library Systems (ILS) in later years to reflect the fact that all functions are managed via a central database (what is today being called a soloed application) with processes that transparently exchange data between functional components such as catalogue records and circulation transactions. By the end of the 1990s some LMSs incorporated interfaces to standard tools such as Microsoft's Excel for the presentation of statistical data [1]. New kinds of enterprise applications have become available to institutions and there is demand for better integration of LMS with such systems [2].

The rapid development in information technology has brought out a revolutionary change in the field of library system management and services. The new information technology had changed the manual scenario of library to computerized automated library. The Radio Frequency Identification (RFID) technology is a latest technology for automatic identification method. RFID has been used in diverse applications from inventory tracking to building access [3]. The concept of RFID can be simplified to that of an electronic barcode and can be used to identify, track or detect library holdings at the circulation desk and in the daily stock maintenance. This system consisting of short RFID labels (tags), hardware, and software provides library with more effective way of managing their collection while providing greater customer services to their regular customers.

Campus Management RFID technology can fully automate various transactions happening within a Campus. Students, teachers, lectures and staff can be provided with RFID smart cards for their attendance and access to various labs and library. Library systems can also be automated by using RFID which can include issuing of books, security gates, searching of books, etc. Assets like computers, electronic equipment and mechanical tools which are constantly 
on the go for student experiments can be tracked to improve their usage by various departments. Hostel can also be better managed with access control system installed for students [4].

RFID started with the advent of radio technology. The Germans, British, Americans and Japanese were all using radar system in 1935 to recognize approaching planes. According to research paper which was prepared in "VU University Amsterdam" Scottish physicist Sir Robert Alexander Watson-Watt showed how his invention of radar could use radio waves to locate physical objects. This was the first big application during World War II, because it detected incoming planes via sending pulses of radio energy and detected the incoming signal which echoes back from planes. But still it could not tell what kind of aircraft was received via signal or to whom they belong [5].

The Radio Frequency Identification and Detection RFID is a technology that has sparked interest in the library community because of its applications that promise to increase efficiency, productivity and enhance user satisfaction. Current library management systems use security strips and barcode technology. Using these technologies, a library management system can keep records of lending, borrowing and shelving status of items such as books, audio or video tapes, CDs, DVDs, etc. But barcodes and security strips have their limitations. They are slow to read and are prone to be stolen. All these led to irreparable loss to a library and its valuable inventory stock. This is where RFID technology can come to the aid of library managers [6, 7]. For further details on RFID research see [8]. In this paper, a RFID system was developed for University of Benin to be integrated into library automation that will provide a comprehensive route for enhancing all library services and upgrade operations for everyone concerned with the library, see [9] for RFID design using MATLAB.

\section{BASIC ELEMENTS OF RFID SYSTEM}

An RFID system is always made up of two components as shown in Figure 1. The transponder is located on the object to be identified, the detector or reader, which, depending upon design and the technology used, may be a read or write/read device. The transponder represents the actual data carrying device of an RFID system, normally consists of a coupling element and an electronic microchip. When the transponder, which does not usually possess its own voltage supply (battery), is not within the response range of a reader it is totally passive. The transponder is only activated when it is within the response range of a reader. The power required to activate the transponder is supplied to the transponder through the coupling unit (contactless) as is the timing pulse and data.

A reader typically contains a high frequency module (transmitter and receiver), a control unit and a coupling element to the transponder. In addition, many readers are fitted with an additional interface (RS 232, RS $485 \ldots$...) to enable it to forward the data received to another system (PC, robot control system etc).

\section{SYSTEM DESIGN AND CONSTRUCTION}

RFID Library Management System is a system that is based on both hardware and software solutions. The hardware requirements are microcontroller, computer system, RFID reader, liquid crystal display (LCD) and a Bluetooth module. While the software requirements are MS Windows 7, Visual Basic, structured query language (SQL) server drivers installed, database (SQL, MS Access, or SQLite) as back end and Windows Presentation Foundation (WPF) as front end.

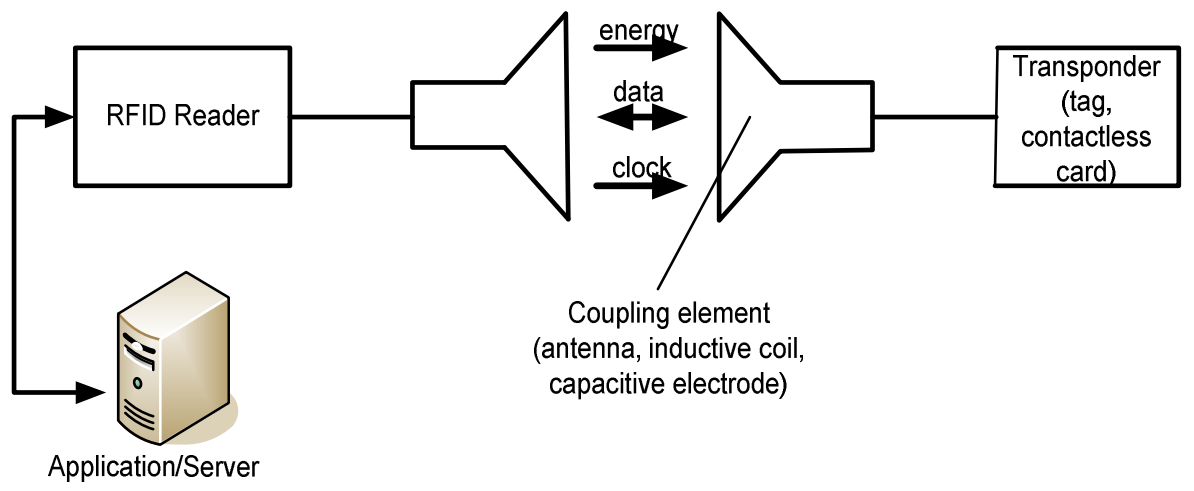

Figure 1: Components of RFID system [10]. 
The features of the system are RFID enabled library for cataloging of books, Bluetooth enabled for easy mobility, flexibility in searching information, centralized database, user identification through their RFID tags and security features that include a login procedure with password protection for both the librarian and members.

\subsection{The Modules}

The various modules that made up the RFID system consist of the following:

\subsubsection{PIC18F4520 Microcontroller}

The PIC18F4520 provides the main control of the device operations. The PIC microcontroller operates at an external clock frequency of $8 \mathrm{MHz}$ provided by the crystal oscillator. It possesses the necessary embedded peripheral (modules) needed for the operation of the device. Such peripherals are the: Enhanced Universal Synchronous Asynchronous Receiver Transmitter EUART and Serial Peripheral Interface (SPI) modules.

\subsubsection{RFID Reader}

The RFID reader module with the on board transceiver (EM4095) is used to read identification cards (RFID cards) using radio waves and the RFID reader continuously transmits a $125 \mathrm{KHz}$ carrier signal using its antenna. The passive RFID tag, embedded in an id card for example, powers on from the carrier signal. Once powered on, the tag transmits back to the reader an FSK encoded signal containing the data stored on the card. The FSK signal is $125 \mathrm{KHz}$ carrier, with $12.5 \mathrm{kHz}$ as the marked frequency, and a $15.625 \mathrm{kHz}$ as the space frequency. The encoded signal is picked up by the reader's antenna, filtered, and processed on the embedded microcontroller to extract the tag's unique identity. At this point the identity can be matched against the records stored on the reader.

The reader performs the following task; continuously transmitting a $125 \mathrm{kHz}$ sinusoidal signal using the antenna, receives and filters the signal returning from the tag, extract the digital data from the processed signal and authenticates the tag using stored records.

\subsubsection{Bluetooth Module}

Over the years, Bluetooth has become the standard for short-range communication. It is preferred over other forms of short-range wireless transmission methods due to its lower power consumption, lower costs and greater signal stability [11]. In this design, the RN-41 Bluetooth module was used as a communication channel between the system device and the personal computer. The RN-41 was hosted on a board designed by Mikroelektronika called "Easy Bluetooth". The Bluetooth board was interfaced with the microcontroller and operates in "cable replacement mode".

The microcontroller directly receives signal from the RFID card reader through its interface ports connection (Pins RB0, RB1, RB2, and RB3). From this the microcontroller sends the digital signal to the Bluetooth module, already software configured to operate in "cable replacement mode". The Bluetooth is an independent circuit from the microcontroller but it is controlled by the microcontroller through attention commands also known as AT command. Through the Bluetooth module, a connection with the host computer is established and then information is transmitted over the wireless channel. The host computer, which is Bluetooth enabled, receives the information through an onboard application which transmits the data using RS232 protocol and the connection to the PC is managed by the software running on the PC.

\subsubsection{LCD module}

To complete the design, a $2 \times 16$ LCD module serves a purpose to display information such as device status and acknowledgment messages. It possesses in it the famous HD44708 LCD controller driver. It supports 2 rows by 16 columns of character making it capable of displaying 32 ASCII characters at once on the screen and as part of the device, users need an interface to monitor the device processes. As the device is programmed, it sends a report to the screen any time a card had been read. The messages displayed depends on the current mode of query i.e. if the shelf number of a book is needed to be known, what would be returned to the screen when a tagged book is read is the shelf number of the book. This way, users (librarian) can quickly move or sort the book to their correct shelf. Apparently its advantage is, multiple books on the shelf can be scanned through and read and books on the shelf that does not belong to the shelf will be displayed on the LCD screen. This is done when the software running on the PC is in "book" 


\section{DEVELOPMENT OF A RFID BASED LIBRARY MANAGEMENT SYSTEM AND USER ACCESS CONTROL, E. O. Edwards \& P. E. Orukpe}

query Tab. This same process applies when a library user (student, Lecturer) had been authenticated.

\subsubsection{Power Supply}

The total power requirements for safe operation of the design is $5 \mathrm{~V}$ at $1.7 \mathrm{~A}$, based on the power requirements of the RFID reader, Bluetooth and the LCD module to successfully transmit and broadcast energy powerful enough to energize the transponder for a successful interrogation.

Using a $12 \mathrm{~V}, 2 \mathrm{~A}$ battery with the aid of LM7805, the $5 \mathrm{~V}$ required to safely operate or power the modules used in the entire circuit was realized. The capacitance value used for the design of the power supply section is not critical. The power supply is as shown in Figure 2 .

\subsection{Circuit operation}

As seen in figure 2, the power supply was designed to give a constant output voltage of $5 \mathrm{~V}$ dc which was realized using LM7805 regulator. The 7805 regulator IC allows an input of $12 \mathrm{~V}$ dc from the power adapter into the supply input pin, capacitor $\mathrm{C} 1$ at the input pin connected in parallel serves to filter out extra noise on the dc power rail. The output pin of the regulator produces constant $5 \mathrm{~V}$ dc required to power the entire circuit. The block diagram of RFID reader for LMS is as shown in figure 3.

The RFID module with four communication buses namely MOD, RDY/CLK, SHD and DEMOD_OUT are interfaced with the microcontroller through its PORTB. EM4095 operation is controlled by logic inputs SHD and MOD. When SHD connected to RB2 is logic high, EM4095 is in sleep mode causing current consumption to reduce. At power up the input SHD has to be high to enable correct initialization. When SHD is low the circuit is enabled to emit RF field, it starts to demodulate any amplitude modulation (AM) signal seen on the antenna. This digital signal coming from the AM demodulation block is provided through DEMOD_OUT pin which is connected to RB0 pin of the microcontroller for decoding and processing. The RDY/CLK connected to RB1 provides the external microcontroller with clock signal which is synchronous with the signal on antenna (ANT 1) the same signal which is being transmitted to the antenna is also put to RDY/CLK pin indicating to microcontroller that it can start observing signal on DEMOD_OUT. High level on MOD pin connected to RB3, forces in tri-state the main antenna drivers synchronously with the RF carrier.

RX and TX of the Bluetooth module are respectively connected to the RX (RC7) and TX pins (RC6) of the microcontroller. The Bluetooth RX pin conveys received serial data from the $\mathrm{PC}$ to the microcontroller. The decoded ID from the RFID module is transmitted over the TX pin of the microcontroller through the Bluetooth module to the PC. For every successful interrogation with RFID tag, the status LED flashes. The status and power LEDs are each connected through a $220 \mathrm{ohm}$ resistor, which are used to limit the current flowing through the LEDs since the LEDs cannot sustain current value more than $25 \mathrm{~mA}$.

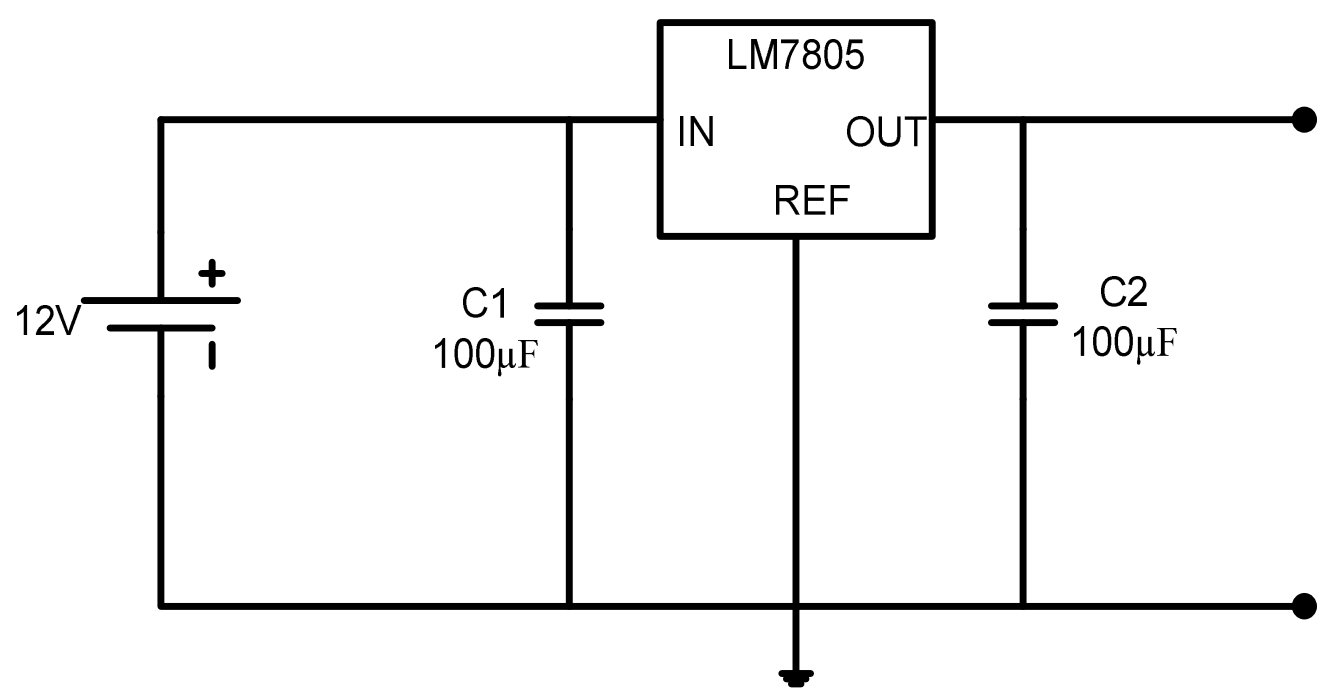

Figure 2: Power supply schematic. 


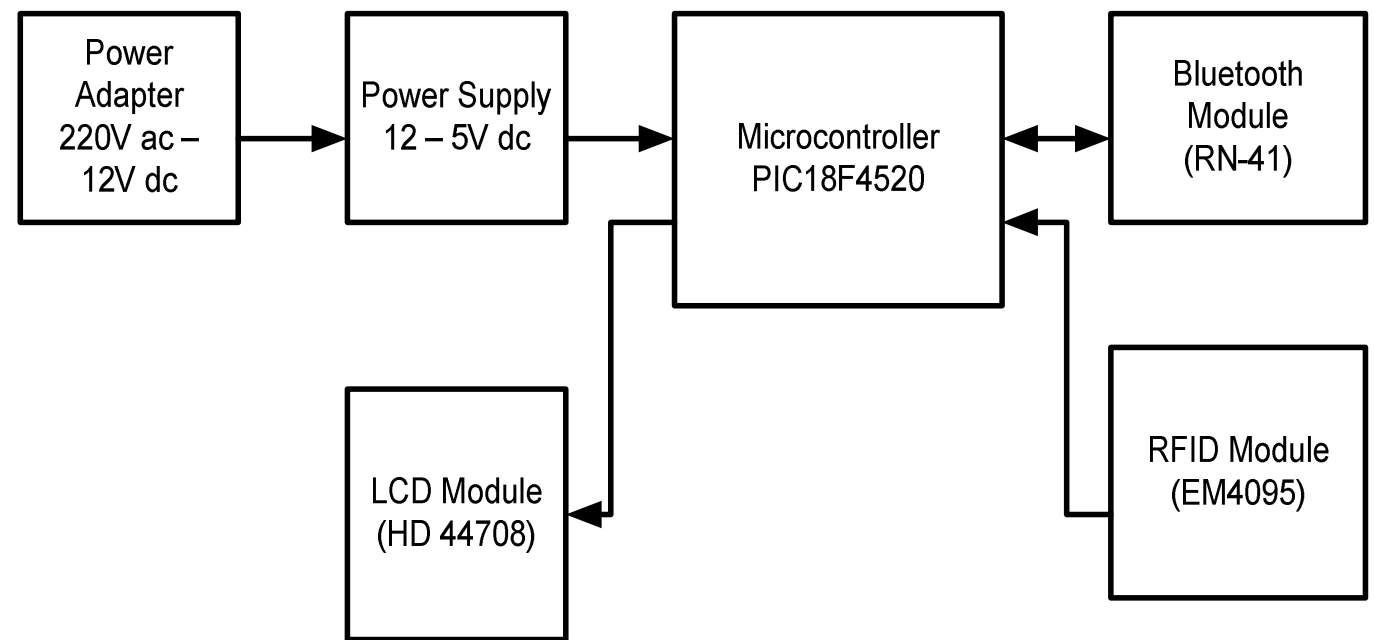

Figure 3: Block Diagram of RFID reader for LMS

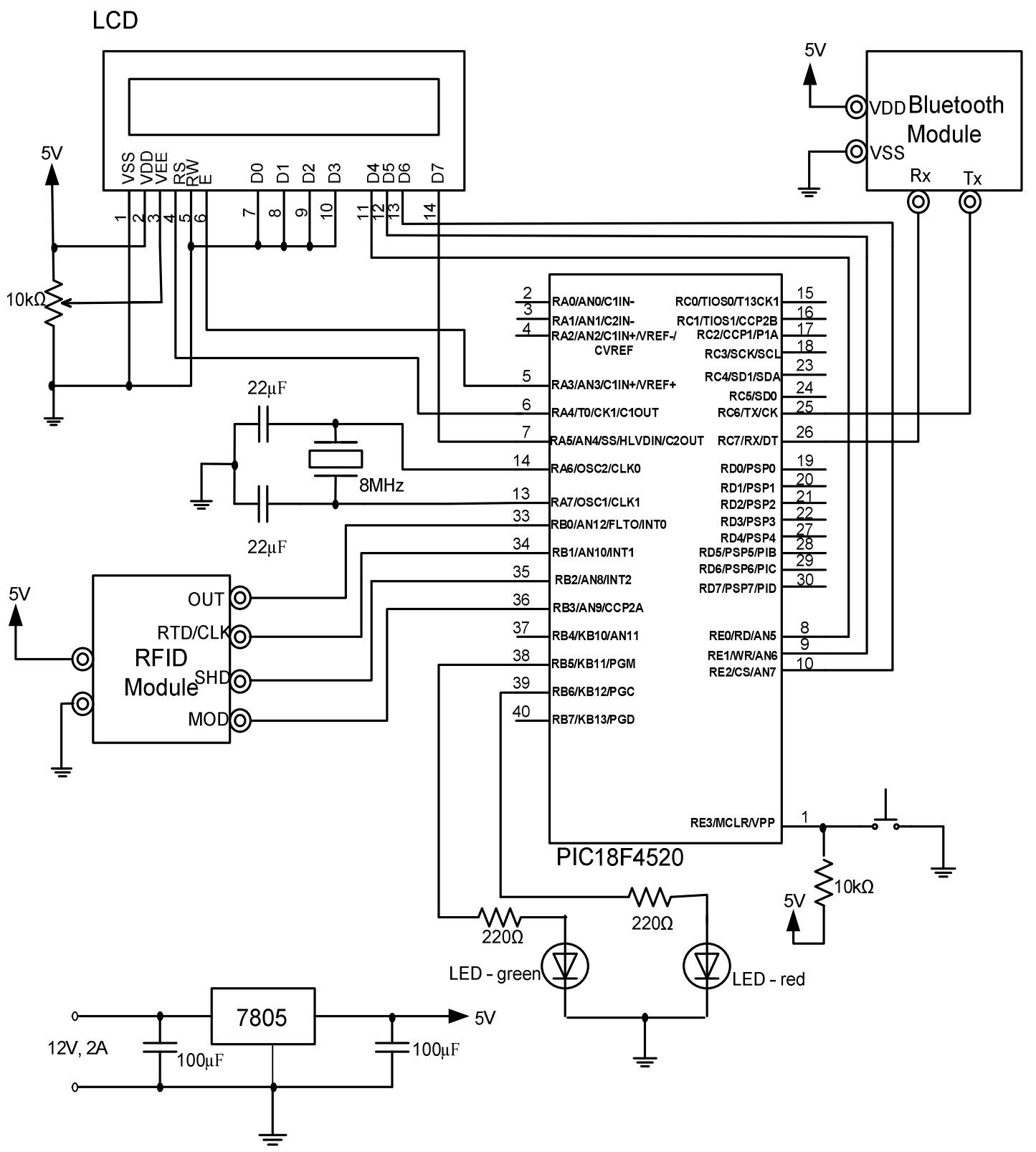

Figure 4: Circuit diagram of RFID reader for LMS. 
The LCD module uses six (6) pins for its correct application due to its use in 4-bit mode. In 4-bit mode, only four (4) buses are used for both data and LCD command communication. When EN pin connected to RA4 is high, communication between LCD module and microcontroller is established. The RS pin is used to select or determine if byte received is commands or ASCII data. Pin VEE connected through a variable resistor is used to adjust the contrast of the display. The complete circuit diagram of the design is as shown in figure 4.

\subsection{Source code}

The software used in this design are C programming language, visual basic and PC software development described as follows:

\subsubsection{C programming language}

In the programming of the microcontroller, MikroC Pro compiler version 5.02 was used for the microcontroller program development. MikroC is a C language compiler IDE which has large embedded number of libraries used for carrying out complex instruction compared with the native assembly language. $C$ language was used to write the source code. The $\mathrm{C}$ programming language is a popular and widely used programming language for developing application PC platform and many other platforms including microcontroller application development [12]. Programmers around the world embrace C programming language, because it gives maximum control and efficiency to the programmer. The benefits of $\mathrm{C}$ language are that it gives room to read and write code for a larger number of platforms and everything from microcontrollers to the most advanced scientific systems can be written in C, and many modern operating systems are written in $\mathrm{C}$. The flow chart for microcontroller is as shown in figure 5.

\subsubsection{Visual Basic}

The application software as a part of this design was developed using Visual Basic, which is an integrated development environment developed by Microsoft and has been used previously in another design [13].

\subsubsection{PC Software Development}

The application software was developed using Microsoft visual studio 2010 ultimate and the application was designed to achieve the following; while it is needed for the PC to communicate with the designed device, it requires carrying out communication over Bluetooth connection. Based on this requirement, the software application was designed with functionality to manage Bluetooth connection with the device. The application also manages the connection between the GUI and the database, through queries executed against the database and the retrieval of query results. The application was designed using Windows Presentation Foundation (WPF) framework. This framework in .NET 4.0 supports a very high graphical user interface control design; therefore the power of this framework was utilized to create a rich graphical user interface (GUI). And more also WPF was used because, Microsoft Corporation may no longer support the conventional windows form in the future.

\subsection{Database table design}

The database consist of four tables (4) which is managed by the LMS application software and a field size of 30 was used for all data type except for the date/time which was fixed.

\subsubsection{Student Info Table}

This table keeps records of registered students with RFID cards as library users, as shown in Table 1.

\subsubsection{Books information table}

Table 2 holds the records of books in the library. It includes the RFIDtag ID as the foreign key (unique field).

\subsubsection{Issue table}

Table 3 is used to store books borrowed by the library users.

\subsubsection{Issue_return table}

Table 4 keeps track of the dates users return borrowed books. A screen shot of the system login is as shown in figure 6 .

\section{SYSTEM OPERATION}

This design and development involves data transfer from PIC18F4520 microcontroller to visual basic program that is running on a computer system. The microcontroller reads data from RFID reader and reports to the computer through the Bluetooth link implemented as serial communication interface with 


\section{DEVELOPMENT OF A RFID BASED LIBRARY MANAGEMENT SYSTEM AND USER ACCESS CONTROL, E. O. Edwards \& P. E. Orukpe}

the PC hosting the database and application software. When Books tagged with RFID is brought close to the reader, the reader continuously read the data encoded inside the card (or tag) until it receives a unique eight (8) character ASCII code. The data read is transferred to the PC currently running the application software from the device with the help of the Bluetooth module. Then the received data is automatically used to query the database depending on the screen tab menu currently being displayed i.e. the screen tab menu are the function of which table is to be queried in the database. Figures 7 and 8 show the application tab for book and user search. To carry out a book search, when the book with its RFID tag is brought close to the reader, based on the tab menu the application selects the right table in the database to query to get the right information of the book. This applies also to other tabs in the application.

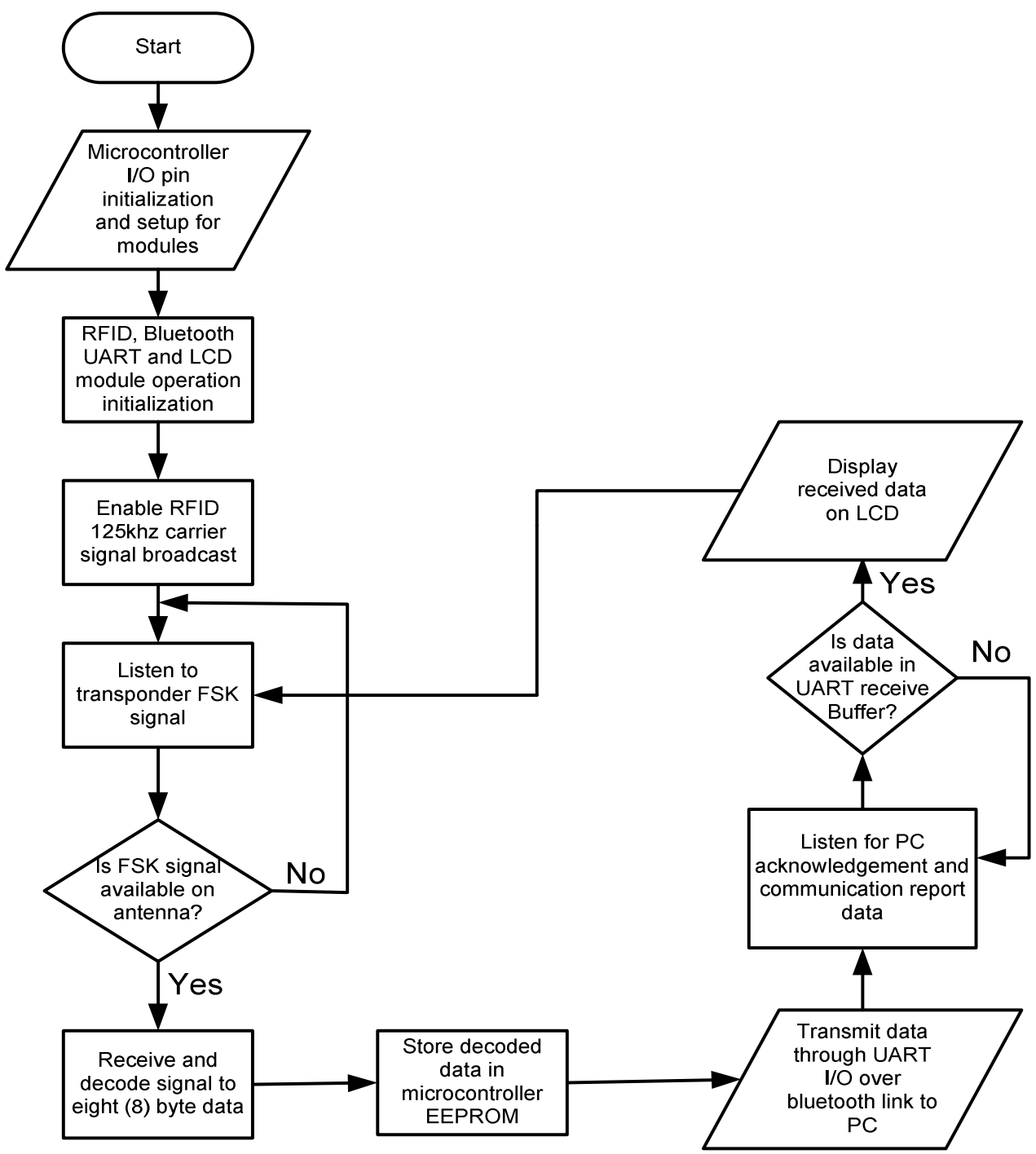

Figure 5: Flow chart for microcontroller operation

Table 1: Student infomation

\begin{tabular}{cccl}
\hline S/N & Field & Data type & Field Description \\
\hline 1 & FirstName & Text & Stores the first name of the regggistered user. \\
2 & LastName & Text & Stores the Lastname of the registered user. \\
3 & MiddleName & Text & Stores the Middlename of the regggistered user. \\
4 & MatNumber & Number & Hold the information of the matriculation number \\
5 & Gender & Text & Stores the gender of the user \\
6 & RFIDTag & Text & This stores the RFID tag ID \\
7 & Borrowed & Number & Stores the number of books borrowed by the user.
\end{tabular}


Table 2: Books information

\begin{tabular}{cccl}
\hline S/N & Field & Data type & Field Description \\
\hline 1 & Title & Text & Stores book's title \\
2 & Author & Text & Stores Author's name \\
3 & ISBN & Text & Stores the ISBN of the book \\
4 & LatestEdition & Text & Provides the latest edition of the book title \\
5 & Publisher & Text & Stores the name of the publisher. \\
6 & BookID & Text & Stores extra unique ID. \\
7 & Copies & Number & Stores the total number of copies. \\
8 & CopiesAvailable & Text & Stores the number of copies available on shelf. \\
9 & shelfID & Text & Stores a common shelf ID \\
10 & RFIDtag & Text & Stores the RFID tag ID and also serves as the table's \\
& & & foreign key. \\
\hline
\end{tabular}

Table 3: Issue table

\begin{tabular}{cccl}
\hline S/N & Field & Data type & Field Description \\
\hline 1 & BookRFIDtag & Text & Stores tag ID, serves as the foreign key. \\
2 & Issue_date & Date/Time & Issue date. \\
3 & Due_date & Date/Time & Stores due date. \\
4 & studentID & Text & Stores user's ID. \\
\hline
\end{tabular}

Table 4: Issue return

\begin{tabular}{cccl}
\hline S/N & Field & Data type & Field Description \\
\hline 1 & RFIDtag & Text & Stores tag ID, serves as the foreign key. \\
2 & Issue_date & Date/Time & Issue date. \\
3 & Due_date & Date/Time & Stores due date. \\
4 & Book_ID & Text & Stores Bookn ID. \\
5 & Return_date & Date/Time & Sores book return date. \\
6 & studentID & Text & Stores borrower's ID \\
\hline
\end{tabular}

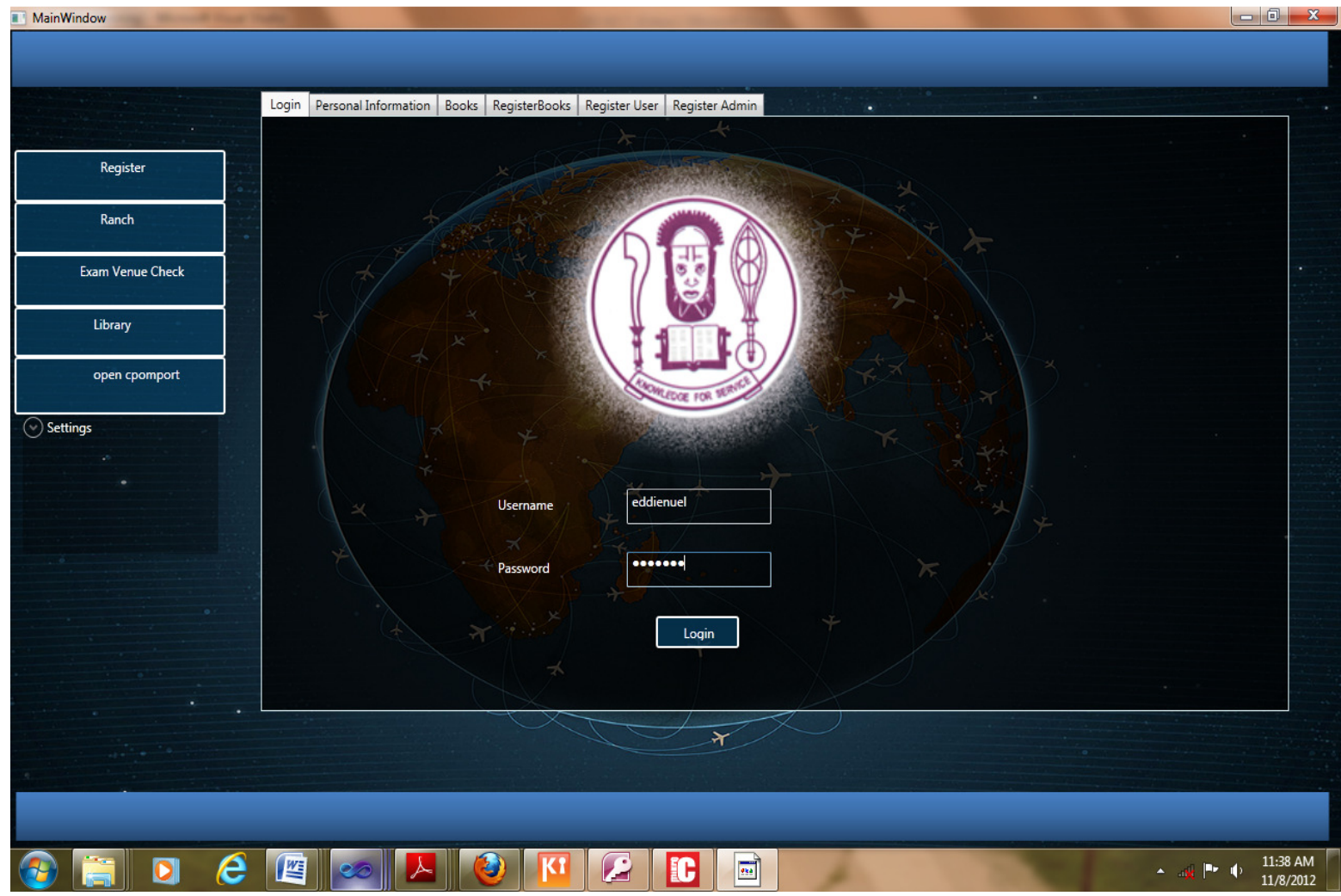

Figure 6: Shot of the login screen 


\section{DEVELOPMENT OF A RFID BASED LIBRARY MANAGEMENT SYSTEM AND USER ACCESS CONTROL, E. O. Edwards \& P. E. Orukpe}

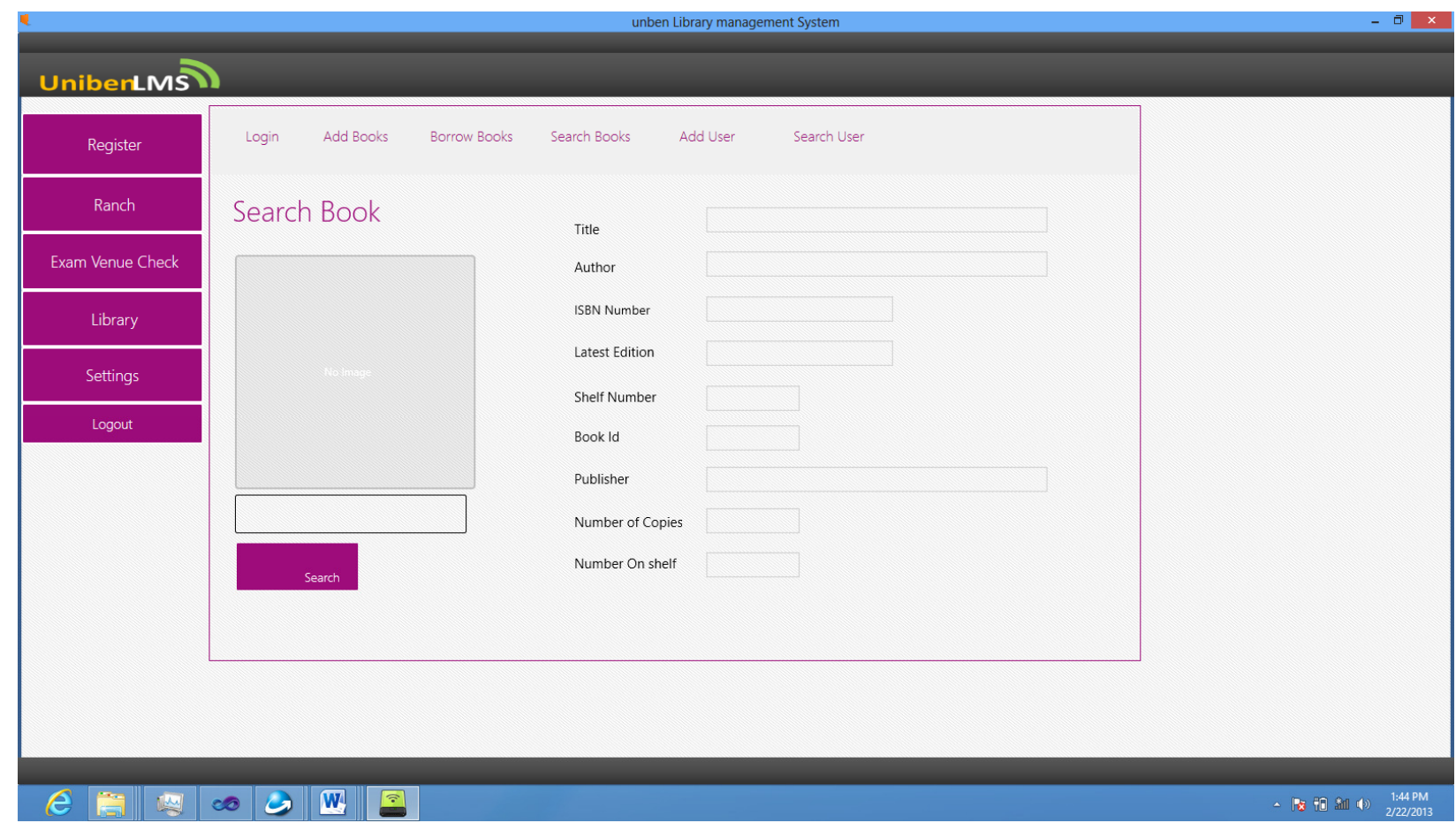

Figure 7: Application displaying tab for checking books information

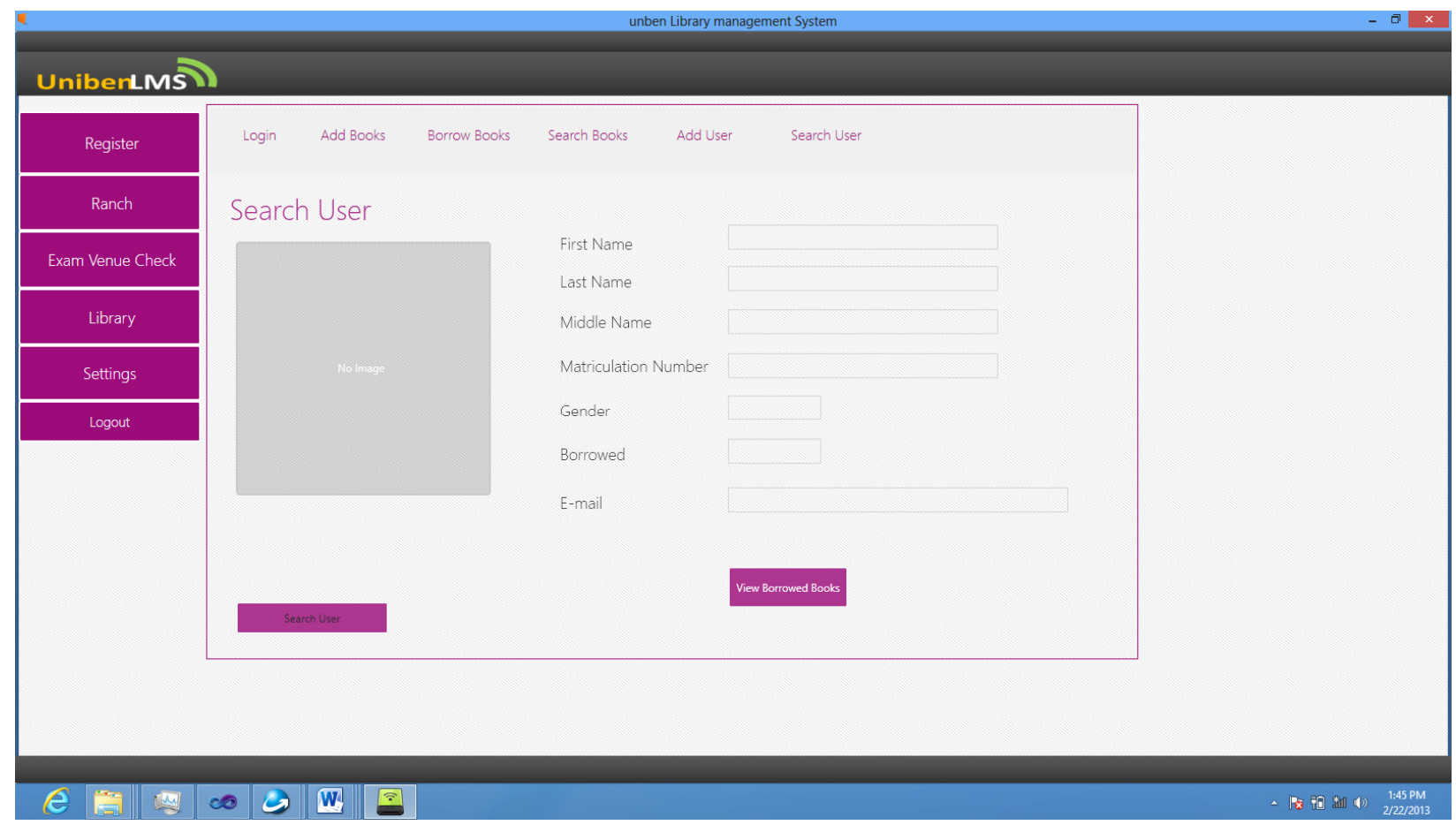

Figure 8: Application displaying tab for checking user information

\section{ANALYSIS AND RESULTS}

At the completion of the design and construction, the system was tested under certain operating conditions, such as different input power supply, obstruction between RFID tag and reader, RFID card angle of interrogation, $\mathrm{PC}$ and device response to data transfer and the maximum distance between device and PC for a reliable communication.

\subsection{Design verification}

The following section describes bench test verification results that confirmed the functionality of the components within the designed system. The major tool used to test the module was EasyPic6 ${ }^{\circledR}$ development board. 


\subsubsection{PIC18F4520 test}

The PIC18F4520 40 pin IC was tested for any internal I/O pin damages that may have occurred. In order to ensure that there were no damages to the pins, a simple program listing was written in C which simply turns on and off the whole 35 I/O pins every one second. This was observed through the array of LEDs connected to the PIC I/O pins on the development board. And a digital multimeter was used to read each pin voltage and the average voltage for all pins was 4.21V for logic HIGH and 0.02V for logic Low. Further step was taken to verify that each time RFID card is moved across the surface of the RFID reader, the microcontroller should report to the computer system providing the necessary information about such a person if eligible or report not registered if otherwise. The tests demonstrated that the microcontroller could read data from the RFID reader and write to the computer system through Bluetooth module using the EasyPic $6^{\circledR}$ development Board.

\subsubsection{Bluetooth test}

In other to ensure correct functionality of the Bluetooth, RN-41 was positioned on the easy Bluetooth board to ensure proper communication with the PC. The easy Bluetooth module has 10 pins that enabled it to be connected to the I/O pin on the development board for proper testing of communication with the microcontroller. The program running on PIC18F4520 was used to set up communication between the Bluetooth and the PC. A test program written in visual basic.net was used to receive and transmit data over the Bluetooth link between the PC and microcontroller. This certified that there was easy communication between microcontroller and PC through Bluetooth. The Bluetooth module from the manufacturer specified that the module can transmit data up to a range of 100 metres which stands to be ok for the design i.e. RFID system can be placed at any strategic position in the library as long as it does not go beyond the tested range with the PC. On the test that was performed, the data communication was only tested for close to 8 metres which is quite ok for its application to the design. It is safe to say that the distance it can transfer depends on the total power input needed by the transmitter at $2.4 \mathrm{GHz}$.

\subsubsection{RFID module test}

RFID was tested using the development board, the RFID card worked well on the board. Cards brought close to the reader where read at an approximate distance of interrogation of 3 centimetres. On design completion, when it was powered with a battery the distance between interrogations was reduced to about 2 centimetres or less. Observations made were recorded in Table 5.

Table 5: Distance between RFID reader and card for interrogation under different power supply.

\begin{tabular}{|c|c|c|}
\hline Power Supply Input & Test board & Distance $(\mathrm{cm})$ \\
\hline $\begin{array}{l}\text { USB board power } \\
(5.0 \mathrm{~V})\end{array}$ & $\begin{array}{l}\text { Development } \\
\text { Board }\end{array}$ & 3.0 \\
\hline Battery $9.0 \mathrm{~V}$ & $\begin{array}{l}\text { Built Target } \\
\text { Board }\end{array}$ & $<2.0$ \\
\hline $\begin{array}{l}\text { DVD power } \\
\text { supply }(12 \mathrm{~V}, 1.0 \mathrm{~A})\end{array}$ & $\begin{array}{l}\text { Built Target } \\
\text { Board }\end{array}$ & $\begin{array}{l}\text { No } \\
\text { interrogation }\end{array}$ \\
\hline $\begin{array}{l}\text { Power Pack } \\
(12 \mathrm{~V}, 2 \mathrm{~A})\end{array}$ & $\begin{array}{l}\text { Built Target } \\
\text { Board }\end{array}$ & Close to $6 \mathrm{~cm}$ \\
\hline
\end{tabular}

\section{CONCLUSION AND RECOMMENDATION}

\subsection{Conclusion}

In this paper, we have developed a RFID based library management system (LMS) using UNIBEN as a case study. The need to manage time consumption is utmost desire of an organization, a firm or an institute. Like it has been discussed, LMS reduces time wasted in performing a particular job by librarian and library staffs. Librarians in the library spend time sorting out books that has been mixed with others on different shelves. But with this system adopted and used, time will effectively be saved in performing such tasks in the library. The designed system worked satisfactorily.

\subsection{Recommendation}

The designed system works well under the condition of its rated power, but never the less the design stands to be a prototype. We intend to improve on this design to read multiple cards or tags by using more sophisticated RFID readers with operating frequency of about $13.56 \mathrm{MHz}$ and interrogate cards over five feet distance away. The system device is required to be mobile and as well handheld; this requires that the device has to be operated on batteries and not on ac adapters. Due to its power requirement, a $12 \mathrm{~V}$ Lithium-Cadmium (Li-Cd) ion rechargeable battery with $7500 \mathrm{~mA}$ capacity can be used to successfully power the device. The integration of a power control system, can also effectively manage power 
consumption by turning off the device automatically when the device is not in use.

\section{REFERENCES}

[1] Jones, D. L., 'The Geac ADVANCE system in the House of Lords Library', Program 27(2), 1993, 123-134.

[2] Haravu, L. J., "Emerging initiatives in library management systems", ICAL Technology, Policy and Innovation, 240-246, 2009.

[3] Zhu, X., Mukhopadhyay, S. K. and Kurata, H. 'A review of rfid technology and its managerial applications in different industries', Journal of Engineering and Technology Management, Volume 29, 152-167, 2012.

[4] Rong, H., Hui, L. and Weiping L. 'The design of people management system in the campus base on rfid, in Lee, G. (Ed.) Advances in Intelligent System, Volume 138, 279 - 286, Springer-Verlag Berlin Heidelberg, 2012.

[5] Rieback, M. R., Crispo, B. and Tanenbaum, A. S. 'The evolution of rfid security' IEEE Pervasive Computing, 62-69, Jan. - March 2006.

[6] Singh J., Brar N. and Fong C. 'The state of rfid applications in libraries'. Information Technology and Libraries, 24-32, 2006.
[7] Yu S. 'Implementation of an innovative rfid applications in libraries', Library Hi Tech, Vol 26 Number 3, 398-410, 2008.

[8] Ngai E. W. T., Moon K. K. L., Riggins F. J. and Yi C. Y., 'RFID resreach: an academic literature review (1995 2005) and future research directions'. International Journal of Production Economics, Vol. 112, 510 - 520, 2008.

[9] Srujana C. , Rama Murthy B., Tanveer Alam K., Sunitha U., Mahammad D. V. and Thimmaiah P. 'Development of RFID based library management system using MATLAB'. International Journal of Engineering and Advanced Technology, Vol. 2, Issue 5, 480-483, 2013

[10] Finkelzeller, K., "The RFID Handbook: fundamentals and applications in contactless smart cards, radio frequency identification and near-field communication", $3^{\text {rd }}$ Edition, John Wiley \& Sons, 2010.

[11] Waseem 0., "Microcontroller design and Bluetooth signal transmission for non-invasive health monitoring system", EE 4B16 Electrical Engineering Biomedical Capstones, Paper 17, 2009.

[12] Verle M., "PIC Microcontrollers - programming in C", $1^{\text {st }}$ Edition, MikroElektonika, 2009.

[13] Orukpe P. E. and Adesemowo A. "Digital control of external devices through the parallel port of a computer using visual basic". Nigerian Journal of Technology, Volume 31, Number 3, 261-267, 2012. 